\title{
Viral vectors expressing immunoregulatory cytokines to treat inflammatory bowel disease
}

Hogaboam CM, Vallance BA, Kumar A, et al. Therapeutic effects of interleukin-4 gene transfer in experimental inflammatory bowel disease. $\mathcal{F}$ Clin Invest 1997;100:2766-76.

Abstract

Inflammatory bowel disease (IBD) is characterised by altered immunoregulation and augmented synthesis of nitric oxide. The purpose of this study was to determine the effects of exogenous IL-4, introduced by a recombinant human type 5 adenovirus (Ad5) vector, on the tissue injury associated with an experimental model of colonic immune activation and inflammation. Colitis was induced in rats by the intrarectal administration of trinitrobenzene sulfonic acid (TNB) dissolved in $50 \%$ ethanol, and control rats received saline via the same route. $1 \mathrm{~h}$ later, all rats were randomized into two groups. The first group was injected intraperitoneally (ip) with $3.0 \times 10^{6}$ plaque forming units (PFUs) of Ad5 transfected with murine interleukin-4 (Ad5IL-4) and the second group was injected ip with the same amount of Ad5 expressing the Escherichia coli Lac $Z$ gene (Ad5LacZ). One-half of the colitic and controls rats were injected again with $3.0 \times 10^{6}$ PFUs of Ad5IL-4 or Ad5LacZ on day 3 of the 6-d study. When introduced once or twice via the peritoneal route into control rats Ad5LacZ was localised to the serosal lining of the peritoneal cavity, the diaphragm and the liver on day 6 . One or two injections of Ad5IL-4 into rats also produced measurable levels of circulating IL-4. TNB-colitis in both Ad5LacZ-treated groups was associated with pronounced elevations in serum IFN- $\gamma$, and mucosal ulceration of the distal colon. Myeloperoxidase and inducible nitric oxide synthase II (NOS II) synthetic activity were also increased by $30-$ and fivefold, respectively, above control levels in the distal colon. However, two injections of AD5IL-4 into colitic rats caused the overexpression of IL-4, and significantly inhibited tissue damage, serum and colon IFN- $\gamma$ levels and myeloperoxidase activity in the distal colon. In addition, NOS II gene expression and NOS II nitric oxide synthesis was significantly inhibited. No therapeutic effect was observed in rats injected once with AD5IL-4. Thus, IL-4, introduced by Ad5, is therapeutic during acute inflammation in the rat colon. The therapeutic effect of IL-4 was associated with an inhibition of inducible nitric oxide expression and a reduction in nitric oxide synthesis.

\section{Comment}

Rats given an intracolonic injection of the contact sensitising agent trinitrobenzene sulphonic (TNBS) acid dissolved in ethanol develop transmural inflammation resembling Crohn's disease. Although the model has limitations, the advantage of the system is that it allows pre-clinical studies on possible treatments to be easily carried out, and it is a much easier system to work with than the spontaneous models of inflammatory bowel disease (IBD) which occur in gene knockout mice. Tissue injury in this model is $\mathrm{T}$ cell mediated, and the response is against both the hapten and the normal flora. The $\mathrm{T}$ cell response is highly skewed towards Th1 and there is abundant interferon (IFN) $\gamma$ and tumour necrosis factor (TNF) $\alpha$ in the mucosa, again like Crohn's disease. As it is now well established that Th1 responses can be dramatically down-regulated by $\mathrm{Th} 2$ cytokines such as interleukin (IL) 4 and IL-10, Hogaboam et al have attempted to find out whether IL-4 prevents TNBS colitis in rats. Raised IL- 4 concentrations can be achieved in vivo by direct injection of recombinant protein, but in this work the authors have used a recombinant human adenovirus 5 vector expressing murine IL-4. The virus was given intraperitoneally and infected cells in the liver, diaphragm, and after two injections, the colon. IL-4 serum concentrations were elevated. The bottom line of the study was that rats given the Ad5 IL-4 vector shortly after induction of colitis and then again three days later, and killed at day 6 , had less tissue injury, lower mucosal IFN- $\gamma$ concentrations, less inducible nitric oxide synthase (iNOS), and fewer neutrophils in the mucosa than rats given a control viral vector.

Immunotherapy as a feasible way of treating chronic IBD has come of age in the past few years with clinical trials of anti-TNF- $\alpha$ therapy, recombinant IL-10, and ICAM-1 antisense. Anti-CD4 therapy was tried and abandoned and recombinant IL-1 receptor antagonist was tried in a few patients but also seems to have lost momentum. A clinical trial using antibodies to the $\alpha 4 \beta 7$ integrin in Crohn's disease, to prevent blood-borne inflammatory

Table 1 Therapeutic procedures which decrease mucosal injury in TNBS models of colitis: they all work

\begin{tabular}{|c|c|}
\hline Modality & Reference \\
\hline Leumedin & f Parmacol Exp Ther 1993;266:468-72 \\
\hline NOS inhibitor & f Parmacol Exp Ther 1993;264:11-16 \\
\hline Lidocaine & Am f Physiol 1994;266:G560-7 \\
\hline Antibiotics & Gut $1994 ; 35: 1090-7$ \\
\hline Anti-IL-12 & $\mathcal{F}$ Exp Med 1995;182:1281-90 \\
\hline Blocking CD40-CD40 ligand & f Exp Med 1995;183:693-8 \\
\hline Anti-integrin antibodies & Clin Exp Immunol 1995;101:351-6 \\
\hline BPC-15 & f Pharmacol Exp Ther 1995;272:417-22 \\
\hline Polyunsaturated fatty acids & f Gastroenterol 1995;30(suppl 8):98-101 \\
\hline Mesylate & f Pharmacol Exp Ther 1996;276:265-70 \\
\hline Butyrate & Gut 1996;38:568-73 \\
\hline \multirow[t]{2}{*}{ Oral tolerance } & f Exp Med 1996;183:2605-16 \\
\hline & f Immunol 1996;157:2174-85 \\
\hline IL-10 or anti-IL-12 & Eur 7 Immunol 1996;26:934-8 \\
\hline Anti-TNF- $\alpha$ & Eur F Immunol 1997;27:1743-50 \\
\hline Pentoxifylline & Aliment Pharmacol Ther 1997;11:575-80 \\
\hline Chemical sypathectomy & Am f Physiol 1997;272:G272-80 \\
\hline IL-4 & f Clin Invest 1997;100:2766-76 \\
\hline
\end{tabular}


cells moving into the mucosa, is about to begin. In deciding which modalities are best to use in patients, it is essential that pre-clinical studies are done using models such as TNBS colitis. There is, however, one problem with this: everything always works, although this may be publication bias. A quick trawl through Medline 1993-98 revealed 17 different modalities, all of which were effective in TNBS colitis in rodents or guinea pigs (table 1).

With this in mind, how do we view the paper by Hogaboam and colleagues? The protocol was highly artificial, the first injection of the vector was given 60 minutes after induction of colitis. Thus the treatment prevented the initial $\mathrm{T}$ cell sensitisation and not chronic disease. This criticism of course depends on whether one considers Crohn's disease a chronic $\mathrm{T}$ cell response or whether during remission there is no $\mathrm{T}$ cell response and exacerbations of disease are essentially de novo. No comparisons for relative efficacy with other modalities were investigated. In a sense, therefore, the paper links established observations-IL-4 inhibits Th1 responses, TNBS elicits a Th1 response and this causes injury in the gut, ergo IL-4 inhibits injury in the gut. A possible confounding factor in patients is that although IL-4 is a potent down-regulator of proinflammatory cytokine production by normal macro- phages, macrophages from patients with inflammatory bowel disease are resistant to this effect. ${ }^{1}$ In my view the most interesting part of the paper is the means of delivery of the cytokine - that is, in a viral delivery system. The Ad5 viral vector is replication deficient and cannot therefore persist in cells. However even transitory expression over a period of a few days is much better, and more physiological, than a large bolus which disappears from the serum in hours or even minutes, and which may have harmful side effects. Moreover, given the success of other modalities in patients I think it very unlikely that IL-4 therapy in the form described by Hogaboam and colleagues will make it into the clinic. Where the paper does make a real contribution is in reinforcing the message that immunotherapy in IBD has a real future.

THOMAS T MACDONALD

Department of Paediatric Gastroenterology,

St Bartholomew's Hospital,

Bartholomew Close,

London EC1A 7BE, UK

1 Schreiber S, Heinig T, Panzer U, et al. Impaired response of activated mononuclear phagocytes to interleukin 4 in inflammatory bowel disease. Gastroenterology 1995;108:21-33. 